\title{
Effects of thymoquinone and curcumin on the regeneration of rat livers subject to $70 \%$ hepatectomy ${ }^{1}$
}

\author{
Orhan Gozeneli', Faik Tatli", Ali Erdal Gunes'"', Muhammed Emin Guldur'v, Abdullah Taskin ${ }^{\vee}$, Osman \\ Bardakcivi, Mehmet Yilmaz ${ }^{\mathrm{VII}}$
}

'Assistant Professor, Department of General Surgery, Faculty of Medicine, Harran University, Sanliurfa, Turkey. Conception, design, scientific and intellectual content of the study; acquisition of data; statistical analysis; manuscript writing; final approval.

"Assistant Professor, Department of General Surgery, Faculty of Medicine, Harran University, Sanliurfa, Turkey. Analysis of data, technical procedures, manuscript writing.

I'Assistant Professor, Department of Hyperbaric and Underwater Medicine, Faculty of Medicine, Harran University, Sanliurfa, Turkey. Analysis of data, statistical analysis, technical procedures, critical revision.

IV Professor, Department of Medical Pathology, Faculty of Medicine, Harran University, Sanliurfa, Turkey. Interpretation of data, pathological examinations.

'PhD, Department of Medical Biochemistry, Faculty of Medicine, Harran University, Sanliurfa, Turkey. Interpretation of data, biochemical parameters.

v'Assistant Professor, Department of General Surgery, Faculty of Medicine, Harran University, Sanliurfa, Turkey. Analysis of data, manuscript writing.

VIIProfessor, Department of Liver Transplantation, Faculty of Medicine, Inonu University, Malatya, Turkey. Manuscript writing, critical revision.

\section{Abstract}

Purpose: To investigate thymoquinone, curcumin and a combination of these two drugs were effective or not at the growth of liver.

Methods: Forty female Wistar-Albino rats distributed into five groups of eight rats each, control, thymoquinone, curcumin, and thymoquinone/curcumin groups. Pathological specimens were studied using the Ki-67 Proliferation Index(PI); and arginase(Arg), tissue plasminogen activator(tPA), ceruloplasmin(Cer) and nitric oxide(NO) were studied in biochemical analysis. Results: Our results showed that Ki-67 proliferation index was low in Groups 1. The proliferation coefficient was significantly higher in the Group 2 and Group 4 than in the Group 1 and Group 3. $(P<0.001$ between Groups 1 and 2, 1 and 4 , and 3 and 4$)$. There was no difference between Groups 2 and $4(P=1)$. The results of the biochemical Arg, tPA and Cer test showed statistically between the Group 1 and Group 2. NO showed significant differences Group 1 and 3.

Conclusions: Thymoquinone and curcumin both have known positive effects on the organism. Histological and biochemical tests showed that thymoquinone is more effective than curcumin.

Key words: Curcumin. Thymoquinone. Hepatectomy. Liver Regeneration. Ki-67 Antigen. Rats. 


\section{Introduction}

The liver, which is the largest internal organ of the human body, is involved in the synthesis of proteins, plays a role in fat digestion via the synthesis bile acids, facilitates the elimination of intrinsic or extrinsic toxic substances, and plays a very important role in energy homeostasis. To perform these functions, both the number of cells in the liver, and the quality of those cells, are very important. Various factors can decrease the amount of liver tissue, for tumor resection or hepatectomy (HT) in living donor liver transplantation (LDLT).

Liver hypertrophy depends on the degree of liver resection ${ }^{1}$. Some people do not have a tumor resection because of the lack of liver tissue that can only be left to themselves. When the number of liver cells decreases, especially when surgery is applied to a part of the liver, a condition called small for size may develop. Various methods have been tried to overcome for this situation.

In the presence of intact liver cells, regeneration occurs with the replication of functioning, mature liver cells. Proliferation stops when the liver reaches its original mass ${ }^{2}$. The regeneration process in LDLT donors is compensatory, and is determined by the body's demand. Liver failure can result from primary liver cirrhosis or the growth of dysfunctional cells within a tumor. In a healthy individual, a reduction in the number or function of lobules leads to hepatic regeneration.

In liver transplantation, the size of the HT is limited by necessity. Drugs that accelerate growth of the remnant donor liver are being tested currently. With extended liver tumor resection, such drugs could increase the amount of normal liver tissue without enlarging tumor growth. Thymoquinone (TQ; 2-isopropyl-5-methylbenzoquinone) and curcumin (C) are antioxidant molecules with hepatoprotective effects. This study examined their roles in liver regeneration.

\section{Methods}

The Inonu University Animal Care and Use Committee (Malatya, Turkey) approved the study (approval number 2016-A18).

In this experimental study, we used 40 female Wistar-Albino rats (10-12weeks old) weighing 200 $250 \mathrm{~g}$ and obtained from the Inonu University Laboratory of Experimental Animals (Malatya, Turkey). The rats were housed in individual cages and allowed to acclimatize for 7 days before the experiment. They were fed commercial pellets ad libitum and had free access to water.

\section{Chemicals}

The chemicals used were obtained from Analiz Medikal (Gaziantep, Turkey). The pathology and biochemical test kits used for the analyses were from Cebel Kimya (Sanliurfa, Turkey) and our hospital.

\section{Study protocol}

After 7 days of acclimatization, the animals were divided into five groups of eight rats each. In groups 2, 3 and 4; TQ, C and $\mathrm{TQ}+\mathrm{C}$ was given before hepatectomy $(\mathrm{HT})$ for 7 days via oral gavage with dose of $100 \mathrm{mg} / \mathrm{kg} /$ day, respectively. Group 1 was kept as Control Group. HT was performed on $8^{\text {th }}$ day to all of the Goups, including Group 1.

The treatments were continued until day 14, excluding control group and the animals in groups 2 to 4 were treated for a total of 14 days. On day 15, the rats were sacrificed with ketamine $75 \mathrm{mg} / \mathrm{kg}$ and xylazine $8 \mathrm{mg} / \mathrm{kg}$ anesthesia. Blood was collected, and serum was separated by centrifugation at $2.000 \times g$ at $25^{\circ} \mathrm{C}$ for 10 minutes. Liver samples were removed and divided into two equivalent sections; 
one was fixed with $10 \%$ formalin solution for histopathological examination and the other was stored at $-80^{\circ} \mathrm{C}$ for biochemical analysis. All samples were treated at room temperature.

\section{Statistical analysis}

All data are expressed as means \pm standard deviation. To evaluate differences in pathological scores among the experimental groups, Kruskal-Wallis analysis of variance was applied, followed by the non-parametric Mann-Whitney $U$ test. $P$-values $<0.05$ were deemed statistically significant. All data were processed using SPSS for Windows software (ver. 22.0; SPSS Inc., Chicago, IL, USA).

\section{Histopathological examination}

Liver specimens taken from the rats were divided into small pieces and fixed in $10 \%$ formaldehyde. Tissue sections were affixed to glass slides and stained with hematoxylineosin (HE) and Ki-67 for immunohistochemical analysis, to determine the liver cell proliferation index. Each stained section was evaluated semi-quantitatively under a light microscope (BX51/×600; Olympus, Tokyo, Japan) by a blind histologist.

\section{Biochemical analysis}

Hepatic tissues were weighed and minced into small pieces before the biochemical analysis. They were placed in empty glass tubes and $1 \mathrm{~mL}$ of $140 \mathrm{mMKCl}$ per gram of tissue was added to each tube. All tissues were homogenized in a motor-driven homogenizer. The homogenate was centrifuged at $2,800 \times g$ for $10 \mathrm{~min}$ at $4^{\circ} \mathrm{C}^{3}$. The resulting supernatant was used for determining arginase(Arg) and tissue plasminogen activator (tPA).

TheNO, ArgandtPAlevelsweremeasured with ELISA kits according to the manufacturers' instructions. Ceruloplasmin(Cer) levels were calculated nephelometrically.

\section{- Results}

\section{Histopathological results}

In Group 1, the proliferation index was $1 \%$ in three rats and $<1 \%$ in five rats. In Group 2 , it was $4 \%$ in six rats and $5 \%$ in two rats; in Group 3, it was $<1 \%$ in four rats and $1 \%$ in four rats; and in Group 4, it was $4 \%$ in five rats and $5 \%$ in three rats (Figure 1 ).

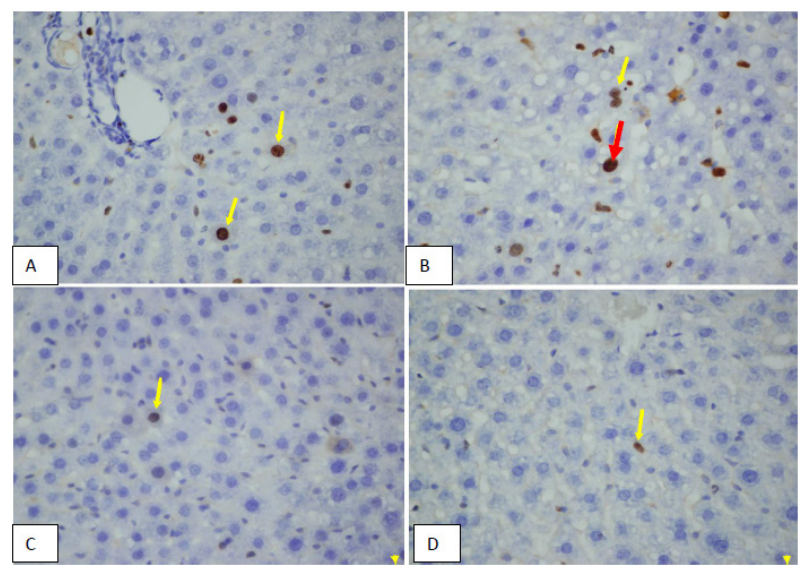

Figure 1 - Examples of positive nuclear staining of liver tissue with Ki-67 (arrows). (A) 4\%, (B) 5\% (red arrow), (C) $1 \%$, and (D)<1\% (Ki-67×600).

The proliferation coefficient was significantly higher in the Group 2 and Group 4 than in the Group 1 and Group 3 alone groups $(P<0.001$ between Groups 3 and 4; 1 and 4; and 3 and 4$)$. There was no difference between Groups 1 and $3(P=1)$.

\section{Biochemical results}

When we examined the biochemical results regarding the proliferation of liver cells, we observed increases in Arg, Cer and tPA in TQ group(Group 2). This increase in the Group 2, Group 3, and Group 4; also led to an additive effect. This increase had a significant effect from the induction of liver cell proliferation(Table 1). 
Table 1 - Serum levels of biomarkers by groups.

\begin{tabular}{llllll} 
Tests & Control(G1) & Thymoquinone(G2) & Curcumin(G3) & $\begin{array}{l}\text { Thymoquinone + } \\
\text { Curcumin(G4) }\end{array}$ & $\boldsymbol{p}$ \\
\hline Arg & $19.04 \pm 8.8$ & $10.99 \pm 2.1^{\circ}$ & $16.88 \pm 6.6$ & $16.48 \pm 6.1$ & 0.031 \\
NO & $7.77 \pm 3.5$ & $4.27 \pm 2.6$ & $4.59 \pm 1.0 \mho$ & $4.43 \pm 1.1$ & 0.014 \\
tPA & $633.56 \pm 143.4$ & $898.06 \pm 159.0^{\psi}$ & $821.61 \pm 427.6$ & $815.03 \pm 220.8$ & 0.013 \\
Cer(U/gr protein) & $793.65 \pm 293.0$ & $604.39 \pm 126.6^{\mathrm{f}}$ & $691.39 \pm 227.4$ & $683.7 \pm 80.8$ & $<0.001$ \\
\hline
\end{tabular}

Values are medians \pm interquartile range

(Arg, Arginase; NO, Nitric Oxide; tPA, Tissue Pasminogen Activator; Cer, Ceruloplasmin)

Significant difference between the TQ and Control groups $\delta, f$ and $\Psi$

Significant difference between the $C$ and Control groups $\mho(P<0.05$ is significant)

\section{- Discussion}

Traditional medicine emerges at an increasing frequency. Liver cells respond positively to some herbal drugs. These include Baccharis trimera, picroliv, ellagic acid and curcumin ${ }^{4,5}$. The positive effects of TQ on liver are also known ${ }^{6-8}$.

TQ is obtained from Nigella sativa seeds, which contain TQ(30-48\%), $p$-cymene (7-15\%), carvacrol (6-12\%), 4-terpineol $(2-7 \%), \quad t$-anethole $(1-4 \%), \quad$ and the sesquiterpenelongifolene $(1-8 \%)^{9}$.

Arg is an enzyme involved in urea cycle, where it catalyzes the hydrolysis of L-arginine into L-ornithine and is expressed specifically in the liver of animals ${ }^{10,11}$. The level of Arg also increases in hepatocellular carcinoma(HCC ${ }^{12}$. The administration of TPA from the outside treats the liver failure by increasing the microcirculation ${ }^{13}$. NO occurs in arterial gas exchange disorders in liver disease ${ }^{14}$. In the absence of Cer, a metalloprotein and an acute phase reactant, Wilson's disease and a number of copper-related complications develops in the brain. Their levels are therefore directly related to the number of liver cells.

It has been shown experimentally that TQ can be used in liver tumors. In mice, aflatoxin (B1) is an effective agent for hepatocellular carcinoma ${ }^{15}$. It is not a nephrotoxic agent when compared to other chemotherapeutics; even the adverse effects of chemotherapy ${ }^{16}$.
Extended liver resection is necessary to obtain clear resection margins in up to $45 \%$ of primary and secondary liver tumors ${ }^{17}$. It strongly reduces the expression of the hyper-argyrophilic nucleolar organizer region in both rat hepatocellular carcinoma and human cholangiocarcinoma. TQ stops cell division in the G2/M phase by inhibiting the phosphoinositide-3-kinase-protein kinase B (PI3K/Akt) and nuclear factor-kB (NF-kB) pathways $^{18,19}$. It reduces the hepatic fibrosis induced by thioacetamide by triggering the LKB1-AMPK pathway ${ }^{20}$. After major liver resection, the mortality rate ranges from 3.2\% to $7 \%$ in patients with undamaged liver tissue, increasing to $32 \%$ in cirrhotic patients ${ }^{21}$.

Liver transplantation is often used to treat chronic liver disease. The calculation regarding the amount of liver to transplant is crucial, because both the recipient and donor may develop liver failure. The remnant liver volume is a key factor in the safety of LDLT ${ }^{22}$. In LDLT, the maximum amount of donor liver removed should be $70 \%$ because liver failure may develop in donors with $<30 \%$ remnant liver tissue ${ }^{23}$. If the remaining liver tissue in the donor is $<30 \%$, small-for-size status and urgent liver transplantation "for liver donors" may occur. Similarly, if insufficient liver is transplanted, the recipient may develop liver failure. TQ, which will be given at doses calculated by specific studies before and after liver transplantation, may be useful in increasing liver volume in 
donors.

Curcuma longa has been used in traditional medicine for thousands of years in India. Curcumin glucuronide is the active metabolite of $C$ and is a natural phenol that is also used as a food coloring (E100). The molecular mechanism underlying the effect of C on the liver involves Hep-G2 gene expression. $C$ has anti-tumorigenic and anti-metastatic effects ${ }^{24}$. Other studies have demonstrated that $C$ protects the liver after $\mathrm{HT}$, increasing both the proliferative index and the mitotic index. C also has antimicrobial, anti-inflammatory, antioxidant, antiviral, antiangiogenic, antidiabetic, and anti-carcinogenic effects in experimental animal models ${ }^{12}$. The diferuloylmethane moiety of $C$ has antioxidant and anti-inflammatory effects without causing toxicity, even at high doses. However, it should be noted that TQ has a narrower therapeutic range than $\mathrm{C}^{25,26}$.

TQ and $C$ also have some unwanted effects. Given at a dose of $50 \mathrm{mg} / \mathrm{kg}$ for 5 days, TQ did not have any side effects on the liver or kidneys in rats. However, the $\mathrm{LD}_{50}$ of TQ was 2.4 $\mathrm{g} / \mathrm{kg}$, at which it reduced the level of glutathione (GSH) enzyme ${ }^{28}$. C at $8 \mathrm{~g} /$ day is well-tolerated, while at $12 \mathrm{~g} /$ day it has mild side effects, such as diarrhea, headache, yellowish feces, and rash $^{29}$. Because of its low bioavailability and rapid half-life, only a small proportion of oral $\mathrm{C}$ reaches the affected area ${ }^{30}$.

\section{Conclusions}

In our study, histologically, the Ki67 proliferation index was low in Groups 1. The proliferation index increased in Groups 2 and 4. $C$ had no marked effects on hepatic proliferation, and no change in proliferation was observed in Group 3.

In chronic liver diseases, liver transplantation is the treatment method using today. Liver obtained from a donor is transferring to the recipient in operation; but extracted liver tissue should be maximum $70 \%$ of donor liver. Regeneration may be faster in patients with liver resection previously given $\mathrm{TQ}$, which accelerates the development of functional lobules.

In addition, if extended resection is to be performed on liver tumors, TQ previously given before the operation may have both chemotherapeutic and regenerative effects on the liver.

\section{References}

1. Ibis C, Asenov $\mathrm{Y}$, Akin $\mathrm{M}$, Azamat IF, Sivrikoz N, Gurtekin B. Factors affecting liver regeneration in living donors after hepatectomy. Med Sci Monit. 2017;23:598693. PMID: 29249797.

2. Taub R. Liver regeneration: from myth to mechanism. Nat Rev Mol Cell Biol. 2004;5(10):836-47. PMID: 15459664.

3. Rabus $M$, Demirbag R, Sezen $Y$, Konukoglu O, Yildiz A, Erel O, Zeybek R, Yakut C. Plasma and tissue oxidative stress index in patients with rheumatic and degenerative heart valve disease. Turk Kardiyol Dern Ars. 2008;36(8):536-40. PMID: 19223719.

4. Girish C, Pradhan SC. Drug development for liver diseases: focus on picroliv, ellagic acid and curcumin. Fundam Clin Pharmacol. 2008;22(6):623-32. PMID: 19049667.

5. Lima SO, Figueiredo M, Santana VR, Santana DPA, Nogueira MS, Porto ES, Andrade RLB, Santos JM, Albuquerque RLC Junior, Cardoso JC. Effect of aqueous extract of the leaves of Baccharis trimera on the proliferation of hepatocytes after partial hepatectomy in rats. Acta Cir Bras. 2017;32(4):263-9. PMID: 28538800.

6. Bilgic S, Tastemir Korkmaz D, Azirak S, Guvenc AN, Kocaman N, Ozer MK. The protective effect of thymoquinone over olanzapine-induced side effects in liver, and metabolic side effects. Bratisl Lek Listy. 2017;118(10):618-25. PMID: 29198130.

7. Hosseini SM, Taghiabadi E, Abnous K, Hariri AT, Pourbakhsh $H$, Hosseinzadeh $H$. Protective effect of thymoquinone, the active constituent of Nigella sativa fixed 
oil, against ethanol toxicity in rats. Iran J Basic Med Sci. 2017;20(8):927-39. PMID: 29085585.

8. Mabrouk A. Protective effect of thymoquinone against lead-induced antioxidant defense system alteration in rat liver. Acta Biol Hung. 2017;68(3):248-54. PMID: 28901799.

9. Burits $M$, Bucar F. Antioxidant activity of Nigella sativa essential oil. Phytother Res. 2000;14(5):323-8. PMID: 10925395.

10.Ohtake A, Takiguchi M, Shigeto Y, Amaya Y, Kawamoto S, Mori M. Structural organization of the gene for rat liver-type arginase. J Biol Chem. 1988;263(5):2245-9. PMID: 2892837.

11.Maharem TM, Zahran WE, Hassan RE, Abdel Fattah MM. Unique properties of arginase purified from camel liver cytosol. Int J Biol Macromol. 2017;108:88-97. PMID: 29180053.

12.Jiang N, Xing YF, Hu B, Tang JX, Dong HM, He YM, Ruan DY.Ye QJ, Cai JR,

Ma XK, Chen J, Cai XR, Lin ZX, Wu XY, Li X. Endoplasmic reticulum stress induced Lox1(+) CD15(+) polymorphonuclear myeloidderived suppressor cells in hepatocellular carcinoma. Immunology. 2017 Dec 6. doi: 10.1111/imm.12876. [Epub ahead of print]

13.Oguz S, Tayar S, Topaloglu S, Calik A, Dinc $\mathrm{H}$, Ozturk $\mathrm{MH}$. Enhancing hepatic microcirculation in postoperative hepatic failure with intra-arterial recombinant tissue plasminogen activator treatment. Exp Clin Transplant. 2017 Dec 18. doi: 10.6002/ ect.2017.0074. [Epub ahead of print]

14.Fallon MB, Abrams GA, Luo B, Hou Z, Dai J, $\mathrm{Ku}$ DD. The role of endothelial nitric oxide synthase in the pathogenesis of a rat model of hepatopulmonary syndrome. Gastroenterology. 1997;113(2):606-14. PMID: 9247483.

15.Nili-Ahmadabadi A, Tavakoli F, Hasanzadeh $G$, Rahimi $H$, Sabzevari O. Protective effect of pretreatment with thymoquinone against Aflatoxin $B(1)$ induced liver toxicity in mice. Daru. 2011;19(4):282-7. PMID: 22615670.

16.Cascella M, Palma G, Barbieri A, Bimonte $S$, Amruthraj NJ, Muzio MR, Del VecchioV, Rea D, Falco M, Luciano A, Arra C, Cuomo A. Role of Nigella sativa and its constituent thymoquinone on chemotherapyinduced nephrotoxicity: evidences from experimental animal studies. Nutrients.
2017;9(6). doi: 10.3390/nu9060625.

17. Broering DC, Hillert C, Krupski G, Fischer L, Mueller L, Achilles EG, Schulte am Esch J, Rogiers X. Portal vein embolization vs. portal vein ligation for induction of hypertrophy of the future liver remnant. J Gastrointest Surg. 2002;6(6):905-13. PMID: 12504230

18.Xu D, Ma Y, Zhao B, Li S, Zhang Y, Pan S, Wu $\mathrm{Y}$, Wang J, Wang $\mathrm{D}$, Pan $\mathrm{H}$, Liu $\mathrm{L}$, Jiang $H$. Thymoquinone induces G2/M arrest, inactivates PI3K/Akt and nuclear factor-kappaB pathways in human cholangiocarcinomas both in vitro and in vivo. Oncol Rep. 2014;31(5):2063-70. PMID: 24603952.

19.Raghunandhakumar S, Paramasivam A, Senthilraja S, Naveenkumar C, Asokkumar S, Binuclara J, Jagan S, Anandakumar P, Devaki T. Thymoquinone inhibits cell proliferation through regulation of $\mathrm{G} 1 / \mathrm{S}$ phase cell cycle transition in $\mathrm{N}$-nitrosodiethylamine-induced experimental rat hepatocellular carcinoma. Toxicol Letters. 2013;223(1):60-72. PMID: 24012840.

20.Bai T, Yang $Y, W u ~ Y L$, Jiang $S$, Lee JJ, Lian LH, Nan JX. Thymoquinone alleviates thioacetamide-induced hepatic fibrosis and inflammation by activating LKB1AMPK signaling pathway in mice. Int Immunopharmacol. 2014;19(2):351-7. PMID: 24560906.

21.Loffroy R, Favelier S, Chevallier O, Estivalet L, Genson PY, Pottecher P, Gehin, S, Krause $D$, Cercueil JP. Preoperative portal vein embolization in liver cancer: indications, techniques and outcomes. Quant Imaging Med Surg. 2015 Oct;5(5):730-9. doi: 10.3978/j.issn.2223-4292.2015.10.04.

22.Taner CB, Dayangac $M$, Akin B, Balci D, Uraz S, Duran C, Killi R, Ayanoglu O, Yuzer $\mathrm{Y}$, Tokat $\mathrm{Y}$. Donor safety and remnant liver volume in living donor liver transplantation. Liver Transpl. 2008 Aug;14(8):1174-9. doi: 10.1002/lt.21562.

23. Ibrahim S, Chen CL, Wang CC, Wang SH, Lin $\mathrm{CC}$, Liu YW, Yang $\mathrm{CH}$, Yong CC, Concejero A, Cheng Y F. Small remnant liver volume after right lobe living donor hepatectomy. Surgery. 2006;140(5):749-55. PMID: 17084717.

24.Bandyopadhyay D. Farmer to pharmacist: curcumin as an anti-invasive and antimetastatic agent for the treatment of cancer. Front Chem. 2014;2:113. PMID: 
25566531.

25.Inokuma T, Yamanouchi $\mathrm{K}$, Tomonaga T, Miyazaki K, Hamasaki K, Hidaka M, Takatsuki $M$, Kanematsu T, Eguchi S. Curcumin improves the survival rate after a massive hepatectomy in rats. Hepatogastroenterol. 2012;59(119):2243-7. PMID: 23435139.

26.Toydemir T, Kanter M, Erboga M, Oguz S, Erenoglu C. Antioxidative, antiapoptotic, and proliferative effect of curcumin on liver regeneration after partial hepatectomy in rats. Toxicol Ind Health. 2015;31(2):162-72. PMID: 23299190.

27.Ali BH, Blunden G. Pharmacological and toxicological properties of Nigella sativa. Phytother Res. 2003;17(4):299-305. PMID: 12722128.
28.Anand $P$, Kunnumakkara $A B$, Newman RA, Aggarwal BB. Bioavailability of curcumin: problems and promises. Mol Pharm. 2007;4(6):807-18. PMID: 17999464.

29.Shoji M, Nakagawa K, Watanabe A, Tsuduki T, Yamada T, Kuwahara S, Kimura F, Miyazawa T. Comparison of the effects of curcumin and curcumin glucuronide in human hepatocellular carcinoma HepG2 cells. Food Chem. 2014;151:126-32. PMID: 24423511.

\section{Acknowledgement}

All of the study participants involved in this investigation; especially to Dr. Turgay Karatas.

\section{Correspondence:}

Prof. Orhan Gozeneli

Harran University, School of Medicine

Mardin Yolu, Osmanbey

Sanliurfa Turkey

Phone: +90 4143444444

Fax: +90 4143183190

opdrog@gmail.com

Received: Oct 18, 2017

Review: Dec 20, 2017

Accepted: Jan 19, 2018
Conflict of interest: none

Financial source: TC Harran University Council of Scientific Research (Project no 15115)
${ }^{1}$ Research performed at Laboratory of Animal Research Center, Inonu University, Malatya, and Harran University, Sanliurfa, Turkey. 